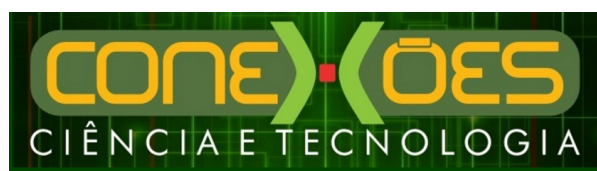

\title{
ESTUDO DO PROCESSO DE DEGRADAÇÃO DE RESÍDUOS SÓLIDOS ORGÂNICOS (RESTOS DE ALIMENTOS) EM LISÍMETRO DE PEQUENO PORTE
}

\author{
Gemmelle Oliveira Santos ${ }^{1}$, Breno de Oliveira Matos ${ }^{1}$ \\ ${ }^{1}$ Instituto Federal de Educação, Ciência e Tecnologia do Ceará (IFCE) \\ <gemmelle@ifce.edu.br>, <matosbreno@gmail.com>
}

DOI: $10.21439 /$ conexoes.v11i4.913

\begin{abstract}
Resumo. O objetivo desta pesquisa foi estudar o processo degradativo de resíduos orgânicos (especificamente restos de alimentos) por meio do monitoramento da temperatura, geração de lixiviado e recalques em lisímetros de pequeno porte. O experimento envolveu a utilização de dois tambores metálicos de 200 litros cada, preenchidos com $150 \mathrm{Kg}$ de restos de alimentos e devidamente equipados para medição dos três parâmetros escolhidos. No lisímetro 1 , a maior temperatura interna foi $42,7^{\circ} \mathrm{C}$ e a menor foi 24,4 ${ }^{\circ} \mathrm{C}$. No lisímetro 2, a maior temperatura foi $45,7^{\circ} \mathrm{C}$ e a menor $25,7^{\circ} \mathrm{C}$. A frequência de temperaturas internas maiores que as externas ocorreram predominantemente no meio do período de monitoramento, ficando claro que a massa de resíduos passou por três fases de degradação: primeira (ajuste inicial), segunda (degradação ativa) e terceira (maturação). O lisímetro 1 gerou $11.265 \mathrm{~mL}$ de lixiviado enquanto que o lisímetro 2 gerou $13.751 \mathrm{~mL}$. O lisímetro 1 gerou aproximadamente 0,075 litros (L) de lixiviado por quilograma $(\mathrm{Kg})$ de resíduo (restos de alimentos). O lisímetro 2 gerou aproximadamente $0,092 \mathrm{~L} / \mathrm{Kg}$. Na primeira semana do monitoramento os lisímetros 1 e 2 apresentaram recalques (média de cinco medições) de 6,3 e 7,4 cm, respectivamente. Na última semana, os recalques foram 12,5 cm (lisímetro 1) e $17,3 \mathrm{~cm}$ (lisímetro 2), sendo mais bruscos no início do monitoramento, concordando com a literatura. Os resultados permitiram concluir que o experimento se mostrou adequado, de baixo custo e sensível para medição dos processos físicos relacionados à degradação dos restos de alimentos, permitindo entender, de certa forma, o que ocorre nos aterros sanitários.
\end{abstract}

Palavras-chaves: Resíduos sólidos. Resíduos orgânicos. Degradação de resíduos orgânicos. Lisímetros.

\begin{abstract}
The purpose of this work was to study the degradation process of organic waste (food waste) by monitoring the temperature, leachate generation and settlements measured with small-sized lysimeters. The experiment involved the use of two 200-liter metal drums filled with $150 \mathrm{~kg}$ of food waste and duly equipped to measure the three chosen parameters. The highest temperature measured by lysimeter 1 was $42.7^{\circ} \mathrm{C}$ and the lowest $24.4^{\circ} \mathrm{C}$. The highest temperature measured by lysimeter 2 was $45.7^{\circ} \mathrm{C}$ and the lowest was $25.7^{\circ} \mathrm{C}$. The frequency of internal temperatures higher than external temperatures occurred predominantly in the middle of the monitoring period, while it is clear that the waste has gone through three different degradation stages: a first stage (initial setting), a second stage (active degradation) and a third stage (maturation). Lysimeter 1 generated $11,265 \mathrm{ml}$ of leachate while lysimeter 2 generated $13,751 \mathrm{ml}$. Lysimeter 1 generated approximately 0.075 liters $(\mathrm{L})$ of leachate per kilogram of waste (food scraps), while Lysimeter 2 generated approximately $0.092 \mathrm{~L} / \mathrm{kg}$. In the first monitoring week, lysimeters 1 and 2 showed a settlement (mean of five measurements) of 6.3 and $7.4 \mathrm{~cm}$, respectively. In the last week, the settlements were $12.5 \mathrm{~cm}$ (Lysimeter 1) and $17.3 \mathrm{~cm}$ (Lysimeter 2). Such settlements were more abrupt at the start of the monitoring, in agreement with the literature. The obtained results let us conclude that the experiment was adequate, low-cost and sensitive to the measurement of the physical processes related to food waste degradation, allowing us to somehow know what happens in a landfill.
\end{abstract}

Keywords: Solid waste. Organic waste. Organic waste degradation. Lysimeters. 


\section{INTRODUÇÃO}

Inúmeros fatores físicos, químicos e biológicos que atuam ora isoladamente ora simultaneamente influenciam na degradação da fração orgânica existente nos resíduos sólidos.

Pela literatura (CARVALHO, 2005; ALCÂNTARA 2007; GARCEZ, 2009, COMPARIN, 2011) a degradação envolve forte atividade microbiana, condições ideais de temperatura, presença de umidade, conversão de substratos, reações cinéticas, desnaturação de enzimas e proteínas, concentração ou diluição de contaminantes, geração de líquidos e gases.

Embora importante, o monitoramento sistemático da degradação dos resíduos sólidos pode ser inviável em aterros sanitários por diversos fatores (distância dos aterros em relação aos centros de pesquisa, tamanho da área, presença de grandes volumes de resíduos, agitada rotina operacional do empreendimento), o que de certo modo justifica a construção e instrumentação de células experimentais de pequeno porte, também denominadas lisímetros.

Os lisímetros permitem analisar os resíduos sólidos antes, durante e depois do seu preenchimento. Com isso, seus resultados ajudam a entender, quem sabe extrapolar, o que realmente ocorre com a massa de lixo após compactação e confinamento nas células dos aterros. Estudos com lisímetros podem contribuir para a redução das lacunas que existem na literatura sobre os processos relacionados à biodegradação de resíduos. Além disso, os lisímetros são experimentos de baixo custo, que simulam com certa segurança fenômenos que só ocorrem nos aterros sanitários e que permitem manipulação de cenários.

Embora usados com frequência no Brasil (SILVA 2002; BARALDI, 2003; SANTOS, 2004; SOUSA 2005; LEITE, 2008, CUNHA, 2009, MEIRA, 2009, SANTOS, 2010, ALVES, 2012, SILVA, 2013), os lisímetros são geralmente preenchidos com resíduos sólidos urbanos que apresentam grande diversidade de materiais em termos de volume e composição, por isso não conseguem traduzir o que ocorre precisamente com os restos de alimentos em degradação.

O objetivo desta pesquisa foi estudar o processo degradativo de resíduos orgânicos (especificamente restos de alimentos) por meio do monitoramento da temperatura, geração de lixiviado e recalques em lisímetros de pequeno porte, com vistas a melhor compreender as fases ou estágios de degradação dos resíduos e avançar no detalhamento da Ciência sanitária e ambiental.

\section{MATERIAIS E MÉTODOS}

A pesquisa foi desenvolvida inicialmente (primeiro mês) em uma área isolada que pertence a Estação de Transbordo do Jangurussu (Fortaleza-CE); local para onde são enviados parte dos resíduos sólidos coletados na cidade. Posteriormente (segundo mês) o experimento foi levado para uma área do Instituto Federal de Educação, Ciência e Tecnologia do Ceará (IFCE), Campus Fortaleza.

O experimento envolveu a utilização de dois tambores metálicos de 200 litros cada (Figura 1) para simular em duplicidade os processos de degradação dos resíduos, reduzir os custos com instrumentação e facilitar o manuseio e monitoramento.

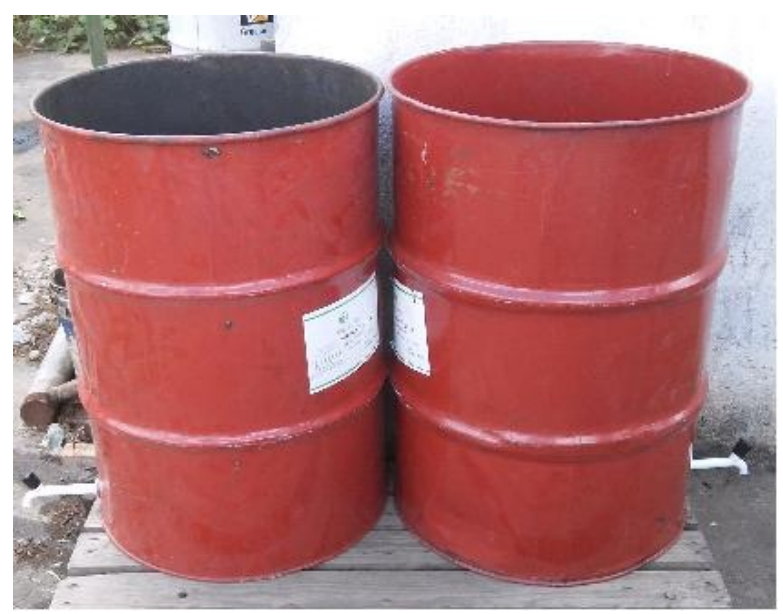

Figura 1: Vista geral dos tambores utilizados.

Em cada tambor foram adicionadas britas para servirem de camada drenante $(5 \mathrm{~cm})$ para os lixiviados (Figura 2p.

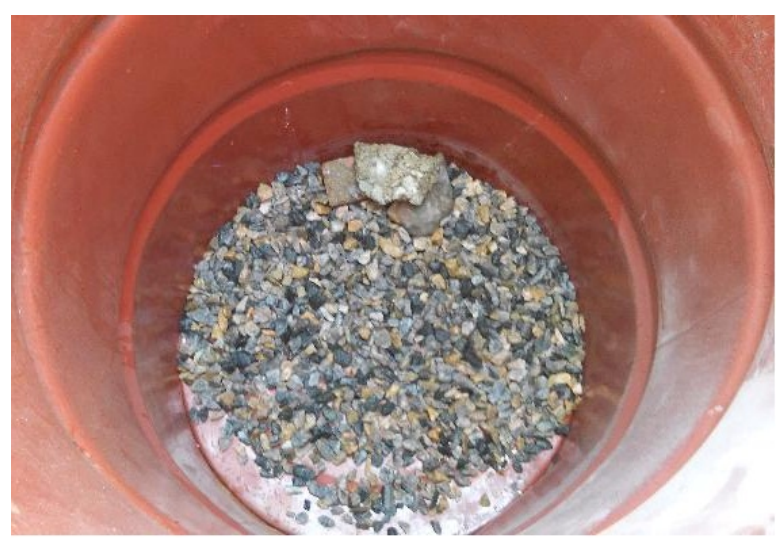

Figura 2: Vista inicial da formação da camada drenante. 
O preenchimento dos tambores foi realizado com os restos de alimentos encontrados no estudo da composição gravimétrica dos resíduos sólidos domiciliares de Fortaleza-CE realizado em 2015.

Foram adicionados $150 \mathrm{Kg}$ de restos de alimentos em cada tambor e o procedimento de compactação aconteceu manualmente a cada 20 - $30 \mathrm{~cm}$ de resíduos (Figura 3).
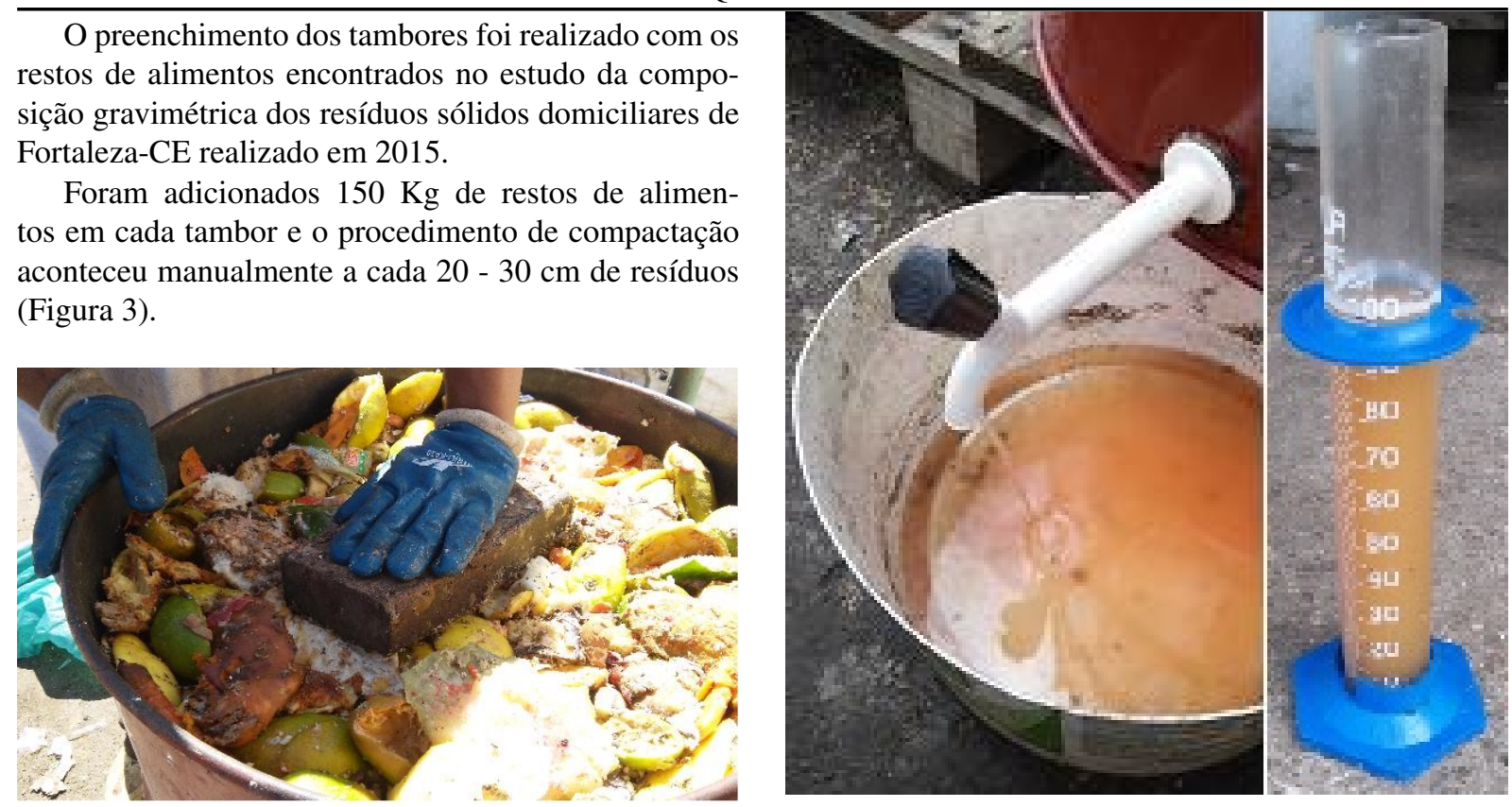

Figura 3: Vista geral dos restos de alimentos e do processo de compactação.

Com o objetivo de monitorar a temperatura de digestão dos restos de alimentos foi instalado um sensor de temperatura no meio dos resíduos (Figura 4) com leitor externo.

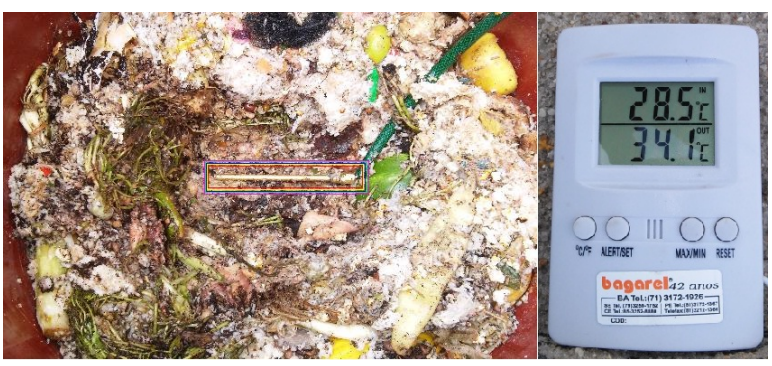

Figura 5: Vista do sistema montado para coleta e medição do lixiviado.

camada $(10 \mathrm{~cm})$ de solo compactado (Figura 6) e, considerando a borda de cada tambor, foram medidos os rebaixamentos (recalques) dos resíduos sólidos com uma trena milimetrada em cinco pontos da cobertura (Figura 7). A cada semana foi extraída a média de medição dos recalques.

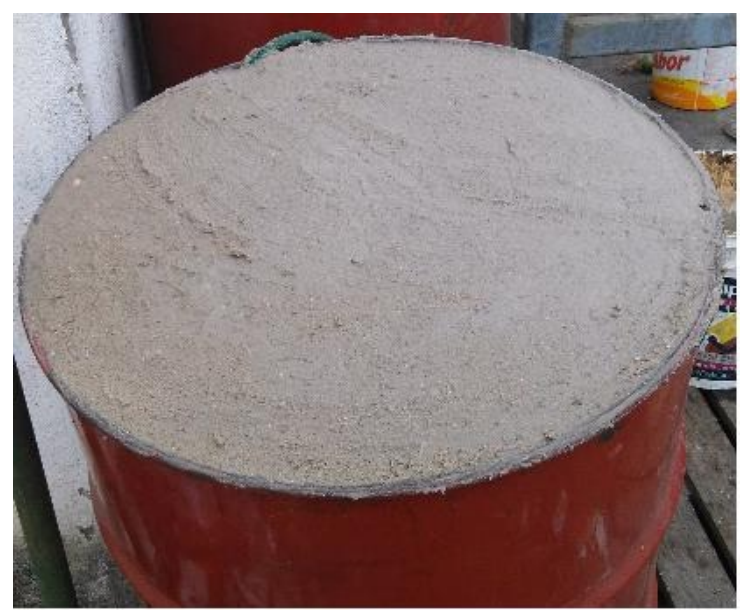

Figura 6: Vista da camada de cobertura realizada sobre o lisímetro. de cada tambor (Figura 5). Foram extraídas 19 medições do volume de lixiviados nos dois lisímetros.

Para simular uma pequena célula de um aterro sanitário, realizou-se a cobertura dos resíduos com uma 


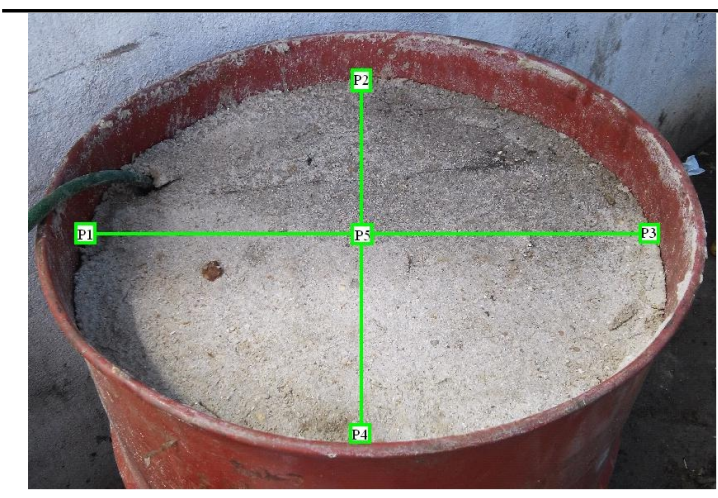

Figura 7: Vista dos pontos da medição dos recalques da camada de cobertura.

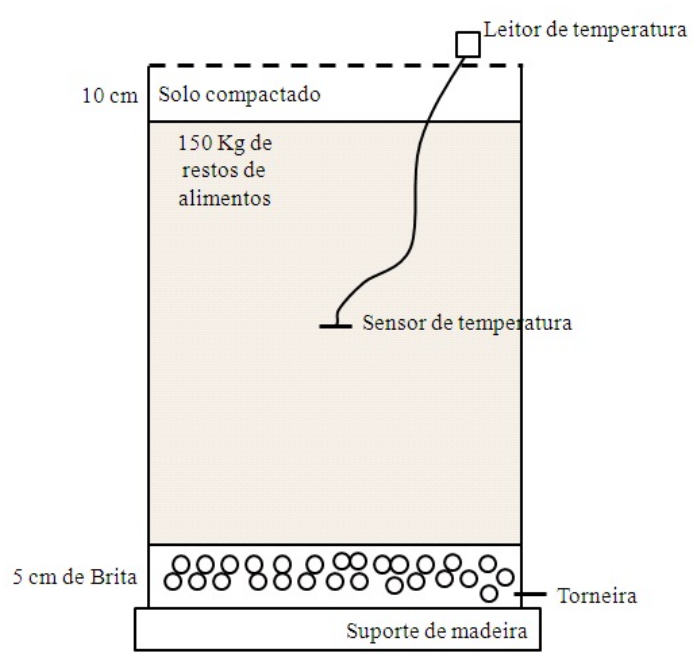

Figura 8: Esquema ilustrativo do experimento.

\section{RESULTADOS E DISCUSSÃo}

A temperatura interna dos resíduos apresentou comportamento geral similar nos dois lisímetros (Figura 9); o que era esperado, pois se trabalhou com resíduos de características (composição, tamanho e idade) semelhantes e mesma compactação.

No lisímetro 1, a maior temperatura interna foi de $42,7^{\circ} \mathrm{C}$ e a menor foi $24,4{ }^{\circ} \mathrm{C}$. No lisímetro 2 , a maior temperatura foi $45,7{ }^{\circ} \mathrm{C}$ e a menor $25,7{ }^{\circ} \mathrm{C}$. Segundo Alcântara (2007) e Cunha (2009), na temperatura ótima as enzimas bacterianas estão na forma mais ativa, enquanto que na temperatura mínima as enzimas não são tão eficientes, causando uma desaceleração no processo de degradação.

Para Mata-Alvarez e Martinez-Virturtia (1986) apud Alcântara (2007), a faixa ótima de operação de aterros sanitários estaria entre 36 e $38{ }^{\circ} \mathrm{C}$, onde, em apenas um ano, haveria uma redução de cerca de $95 \%$ da

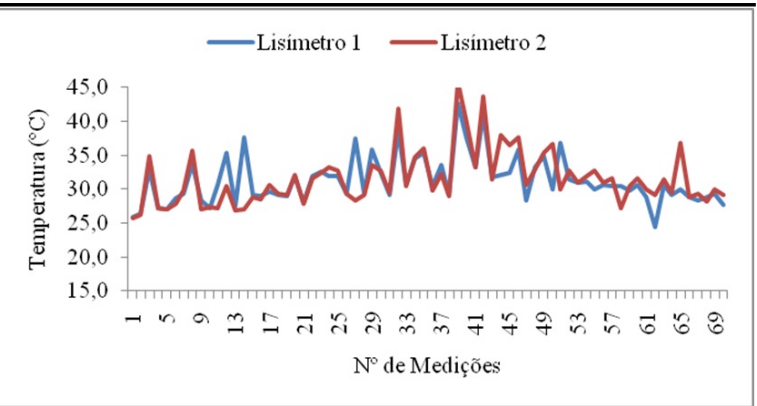

Figura 9: Temperatura interna e externa dos restos de alimentos nos lisímetros.

matéria orgânica biodegradável. Qdais e Alsheraideh (2008) mediram $38^{\circ} \mathrm{C}$ como a temperatura ideal para a maior a taxa de degradação.

Diversos autores citados por Teixeira (1993) apontam como faixa ótima ou ideal o intervalo entre $30{ }^{\circ} \mathrm{C}$ e $40^{\circ} \mathrm{C}$. Santos (2010) afirma que temperaturas abaixo de $22{ }^{\circ} \mathrm{C}$ podem ter afetado negativamente a taxa de crescimento dos microrganismos mesófilos em seu experimento e podem ser consideradas baixas quando comparadas as de aterros sanitários ou mesmo outros lisímetros.

A amplitude da temperatura no lisímetro 1 foi de $18,3{ }^{\circ} \mathrm{C}$ e no lisímetro 2 foi $20,0{ }^{\circ} \mathrm{C}$. Santos (2010) verificou amplitude de $7{ }^{\circ} \mathrm{C}$, enquanto Comparin (2011) verificou amplitude de $15^{\circ} \mathrm{C}$ entre máximas e mínimas. A conclusão de Cunha (2009) pode ser aplicada a esta pesquisa: grandes flutuações de temperaturas são típicas nas camadas superficiais de um aterro como resultado de mudanças na temperatura do ar ambiente. Conclusão semelhante foi feita por Jucá e Maciel (1999), Carvalho (2005), Monteiro et al. (2006), Garcez (2009), Meira (2009), Santos (2010), Comparin (2011), Alves (2012).

As temperaturas médias observadas nos dois lisímetros $\left(31,3\right.$ e $\left.31,5^{\circ} \mathrm{C}\right)$ apontam para provável predominância de microrganismos mesófilos, considerando a classificação feita por Carvalho (2005), Garcez (2009), Comparin (2011).

Alcântara (2007) registrou temperaturas estabilizadas em torno de $30{ }^{\circ} \mathrm{C}$ durante a maior parte do tempo de monitoramento. Cunha (2009) mediu temperaturas oscilando em torno de 26 a $32{ }^{\circ} \mathrm{C}$. Garcez (2009) e Meira (2009) mediram temperaturas iniciais no interior dos seus lisímetros de aproximadamente $40{ }^{\circ} \mathrm{C}$. Carvalho (2005), em seis lisímetros, observou temperatura em torno de $24,05{ }^{\circ} \mathrm{C}$.

Conforme Junqueira (2000) os microrganismos que agem na massa do lixo não controlam as suas tempe- 
raturas internas, ficando suscetíveis às mudanças que ocorrem na temperatura do meio em que se encontram.

Como se observa na Figura 9 , picos de temperatura se repetiram com certa frequência ao longo do monitoramento. Conforme Junqueira (2000) a variação da temperatura ocorre em função de diversos fatores, tais como, infiltração de águas da chuva e mudança nas condições de oxigênio dentro do lixo. Alcântara (2007) mediu em seus lisímetros picos de $45^{\circ} \mathrm{C}$ e $55^{\circ} \mathrm{C}$.

A frequência de temperaturas internas maiores que as externas ocorreram predominantemente no meio do período de monitoramento, ficando claro que a massa de resíduos passou por três fases de degradação: primeira (ajuste inicial), segunda (degradação ativa) e terceira (maturação), como mostram as Figuras 10 e 11 .

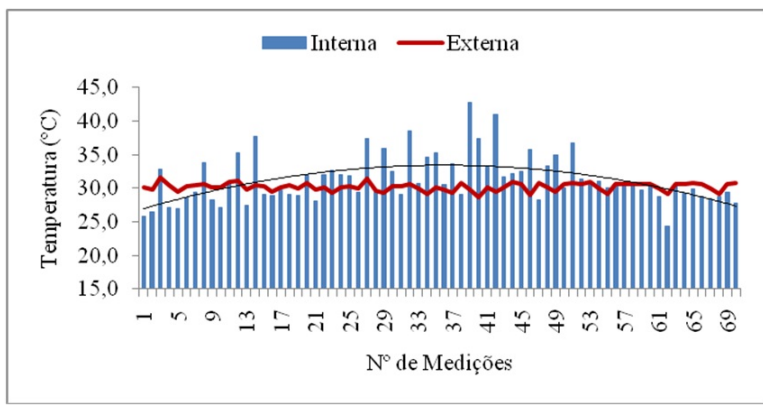

Figura 10: Temperatura interna e externa dos restos de alimentos no lisímetro 1 .

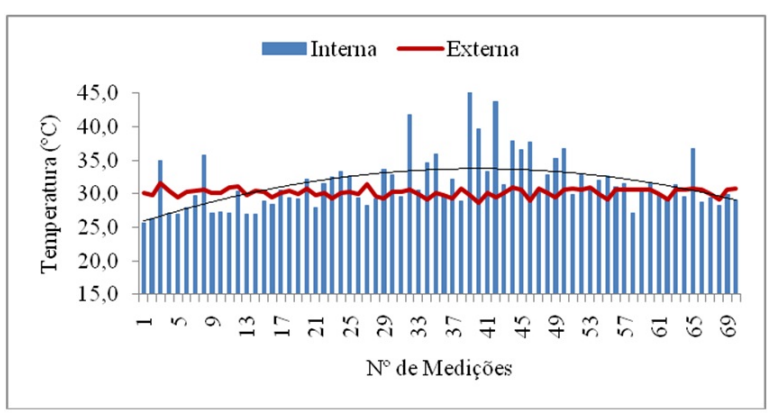

Figura 11: Temperatura interna e externa dos restos de alimentos no lisímetro 2.

Conforme Monteiro et al. (2006), após disposição dos resíduos em lisímetros, o aumento da temperatura é esperado e provavelmente está relacionado a microrganismos aeróbios - fungos, bactérias e actinomicetos - que ao degradarem a matéria orgânica a compostos mais simples como $\mathrm{CO}_{2}$ e $\mathrm{H}_{2} \mathrm{O}$ liberam calor, caracterizando um processo exotérmico. Para Kasam (2013) o potencial redox dentro de um aterro sanitário é que determina o mecanismo de degradação dos resíduos.

A predominância da fase aeróbia no experimento pode ser justificada de várias formas: (1) o lento processo de preenchimento dos lisímetros expôs os resíduos ao ambiente externo e permitiu entrada de ar (oxigênio) no meio, (2) a realização da camada de cobertura aprisionou o ar dentro dos lisímetros, (3) provável existência de trocas gasosas entre o meio interno e externo pela camada de cobertura, algo já conhecido na literatura para esse tipo de experimento.

Segundo Junqueira (2000) a entrada de uma carga extra de oxigênio dissolvida em água favorece o incremento das atividades de bactérias aeróbias ou anaeróbias facultativas, provocando um aumento da temperatura no interior da massa de lixo. $\mathrm{O}$ arejamento da massa de lixo produz uma rápida oxidação de compostos (ERSES; ONAY; YENIGUN, 2008).

Conforme Alcântara (2007), os resíduos dispostos nos aterros carregam em seus vazios grandes quantidades de oxigênio molecular, o que possibilita a biodegradação sob condições aeróbias. Nessa fase, que pode durar várias horas a uma semana, dependendo das características de compactação e umidade da massa de resíduos, ocorre o processo de hidrólise sob condição aeróbia e a principal fonte de carbono para a atividade dos microrganismos provém de açúcares solúveis. Devido a essas reações aeróbias exotérmicas da fase inicial, pode ser observado um aumento considerável na temperatura.

No geral, a temperatura interna no lisímetro 1 superou a temperatura externa em 33 das 70 medições $\left(47,1 \%\right.$ ), tendo ficado (média) $3,9^{\circ} \mathrm{C}$ acima da temperatura ambiente (valor máximo alcançado: $12,9^{\circ} \mathrm{C}$ ). A temperatura interna no lisímetro 2 superou a externa em 35 das 70 medições $(50,0 \%)$, tendo ficado, em média, $4,4{ }^{\circ} \mathrm{C}$ acima (valor máximo: $15,9^{\circ} \mathrm{C}$ ). A pesquisa de Carvalho (2005) registrou $6^{\circ} \mathrm{C}$ de diferença média entre a temperatura interna e a externa.

No lisímetro 1, a primeira fase (ajuste inicial) ocorreu entre a $1^{\mathrm{a}}$ e a $21^{\mathrm{a}}$ medição (temperatura interna menor que a temperatura externa), a segunda fase (degradação ativa) ocorreu da $22^{\mathrm{a}}$ até a $51^{\mathrm{a}}$ medição (temperatura interna maior que a externa) e a terceira fase (maturação) ocorreu da $52^{\mathrm{a}}$ até a $70^{\mathrm{a}}$ medição (interna $<$ externa). No lisímetro 2 , as fases ocorreram de forma semelhante: ajuste inicial ( $1^{\mathrm{a}}$ e a $22^{\mathrm{a}}$ medição), degradação ativa ( $23^{\mathrm{a}}$ até a $55^{\mathrm{a}}$ medição), maturação (56 até a $70^{\mathrm{a}}$ medição).

Os dois lisímetros mostraram correlação positiva entre os resultados da temperatura interna e o horário da medição ao longo do dia, mostrando influência do 
ambiente externo, concordando com extensa literatura inter(nacional): Jucá e Maciel (1999), SIDA (2004 1 Carvalho (2005), Monteiro et al. (2006), Garcez (2009), Meira (2009), Cunha (2009), Santos (2010), Comparin (2011).

Segundo Alcântara (2007), para reduzir a interferência da temperatura ambiente no processo de degradação em lisímetros, as paredes do mesmo devem ser construídas em alvenaria de tijolos cerâmicos, pois se constituem em um material de baixa condutividade térmica e elevado calor específico e, portanto, contribuem para diminuir a troca de calor com o meio externo, evitando variações bruscas de temperatura. Já Alves (2012) concluiu que as paredes da sua célula experimental (feitas de alvenaria) não foram isolantes.

O lisímetro 1 gerou $11.265 \mathrm{~mL}$ de lixiviado enquanto que o lisímetro 2 gerou $13.751 \mathrm{~mL}$. Pela literatura, vários fatores justificam o fato do lisímetro 1 ter gerado menos lixiviado: (1) perda de água durante seu enchimento, uma vez que houve exposição da massa de lixo ao ambiente (MONTEIRO et al., 2006), (2) menor teor de umidade inicial em seus materiais (FIRMO 2013) e (3) maior capacidade dos seus resíduos reterem água em função de um conteúdo mais elevado em matéria orgânica (SIDA, 2004, SILVA, 2014).

O lisímetro 2, por sua vez, deve ter gerado mais lixiviado, entre outros fatores, porque recebeu chuvas (SIDA, 2004) enquanto estava sendo preenchido (a cidade de Fortaleza registrou 80 milímetros), enquanto o lisímetro 1 já estava com a camada de cobertura no dia que choveu. A Figura 12 mostra o lisímetro 2 produzindo lixiviado antes mesmo do seu completo preenchimento com restos de alimentos.

Conforme Giordano, Filho e Carvalho (2011), a entrada de água nas células do aterro contribui decisivamente para aumentar a produção do chorume. Costa e Silva (2014) observou que as alterações dos volumes de lixiviados em sua pesquisa foram influenciadas pelas chuvas.

O volume de lixiviado (Figura 13) apresentou comportamento geral decrescente ao longo dos dias de monitoramento, como esperado. No primeiro dia de medição, o lisímetro 1 gerou $4.485 \mathrm{~mL}$ e no último dia $(17 / 09 / 2015)$ essa geração foi $99,3 \%$ menor $(33,3 \mathrm{~mL})$. O lisímetro 2 gerou $3.350 \mathrm{~mL}$ no primeiro dia de monitoramento e no último dia sua geração foi $95,2 \%$ menor (162,2 mL).

O decaimento do fluxo de lixiviado no lisímetro 2, de uma medição para outra, foi menos brusco (desvio padrão: $968 \mathrm{~mL}$ ) que no lisímetro 1 (desvio padrão:

\footnotetext{
${ }^{1}$ SWEDISH INTERNATIONAL DEVELOPMENT COOPERATION AGENCY (SIDA)
}

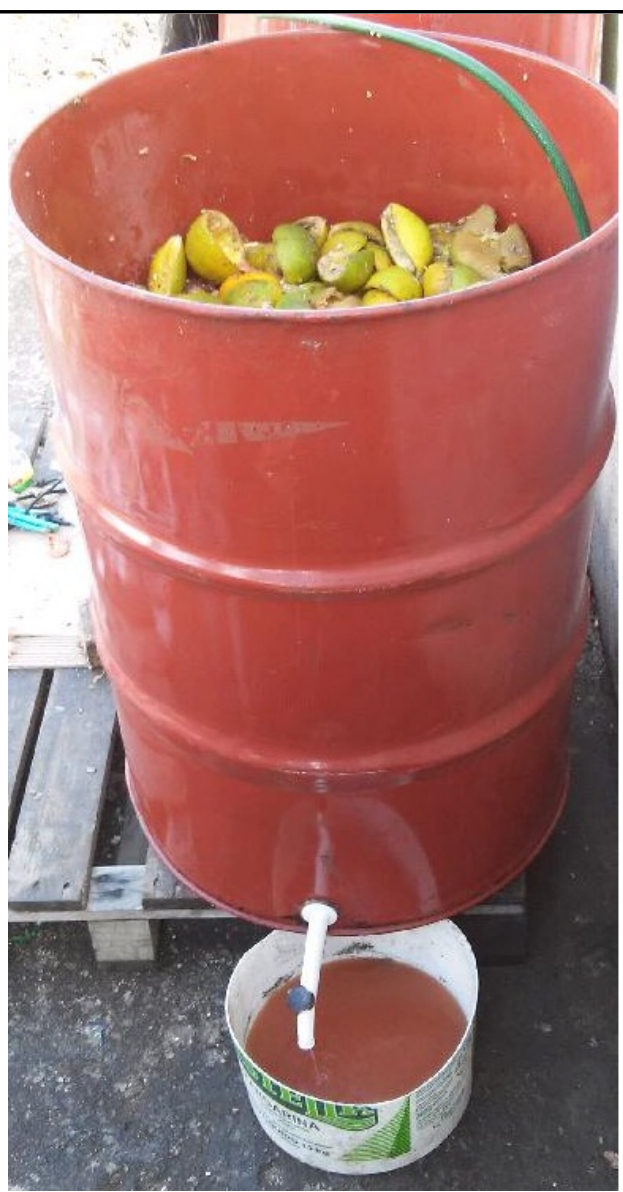

Figura 12: Vista do lisímetro 2 produzindo lixiviado.

$1.226 \mathrm{~mL}$ ) e isso pode está associado à in(existência) de caminhos preferenciais e espaços vazios, além das taxas de permeabilidade.

O grau de compactação e o tamanho dos resíduos também influenciam no fluxo dos líquidos, mas estas duas variáveis não devem ter destaque no experimento, pois se trabalhou com o mesmo tipo de resíduo (restos de alimentos) e com a mesma compactação. Conforme SIDA (2004) a capacidade de campo e a porosidade dos resíduos diminui com o tempo à medida que a degradação dos resíduos ocorre.

A saída de líquidos do experimento provavelmente reduziu o ritmo de biodegradação dos restos de alimentos, pois o lixiviado acaba arrastando nutrientes importantes, reduzindo a umidade do meio e a diluição de possíveis materiais inibidores existentes nos resíduos. Por outro lado, a saída de líquidos pode ser interpretada como vantajosa, pois reduz significativamente a carga de poluentes de um aterro (CHIEMCHAISRI et al. 2002).

O lisímetro 1, gerou aproximadamente, 0,075 litros 


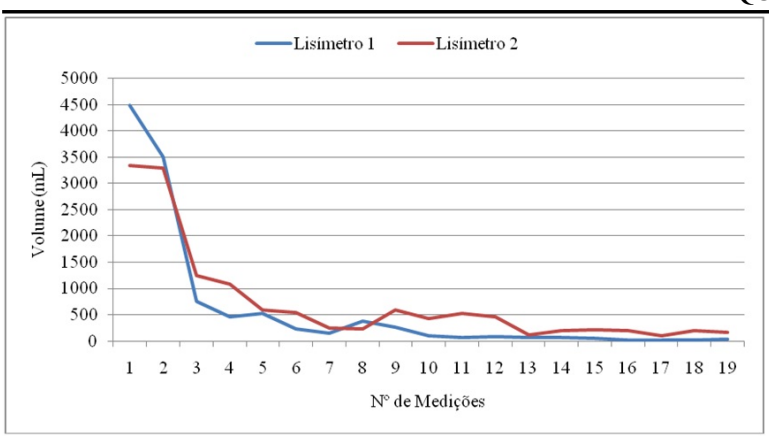

Figura 13: Comportamento do volume $(\mathrm{mL})$ de lixiviado extraído dos lisímetros.

(L) de lixiviado por quilograma $(\mathrm{Kg})$ de resíduo (restos de alimentos). O lisímetro 2 gerou aproximadamente $0,092 \mathrm{~L} / \mathrm{Kg}$. Os resultados da literatura são menores que os desta pesquisa: Teixeira e Pansani (2002) - 0,063 $\mathrm{L} / \mathrm{Kg}$; Simão (2014) - 0,450 L/Kg, cabendo destacar que os lisímetros da literatura são de porte diferente e não foram preenchidos apenas com restos de alimentos, como nesta pesquisa.

Conforme Cunha (2009) o volume produzido depende, substancialmente, do líquido proveniente da própria umidade do lixo, de água de fontes externas e dos líquidos gerados no processo de decomposição biológica. Gamage et al. (2010) apontam que os lixiviados em lisímetros são os melhores indicadores da biodegradação.

Os volumes de lixiviados, relativamente expressivos para o porte do experimento, podem estar relacionados a um intenso processo aeróbio de degradação inicial. Além disso, cabe considerar outros fatores: a presença de elevados teores de umidade nos restos de alimentos (provavelmente maior no lisímetro 2 que no lisímetro 1), a presença de espaços vazios que permitem mais facilmente a percolação/saída de líquidos, e mudanças na temperatura interna dos resíduos, que interferem na cinética das reações de biodegradação.

Outra característica do experimento foi a perceptível mudança de cor dos lixiviados ao longo dos dias de monitoramento (Figura 14).

Resultado semelhante foi apresentado por Silva (2014), que observou aumento dos valores da cor com o tempo de aterramento e Carvalho (2005), que associou o aumento da cor com a presença de lixo novo.

Para Monteiro et al. (2006) a degradação inicial dos resíduos por microrganismos permite a transformação dos compostos complexos em subprodutos menos complexos e esta transformação certamente altera a qualidade física, química e biológica dos lixiviados.

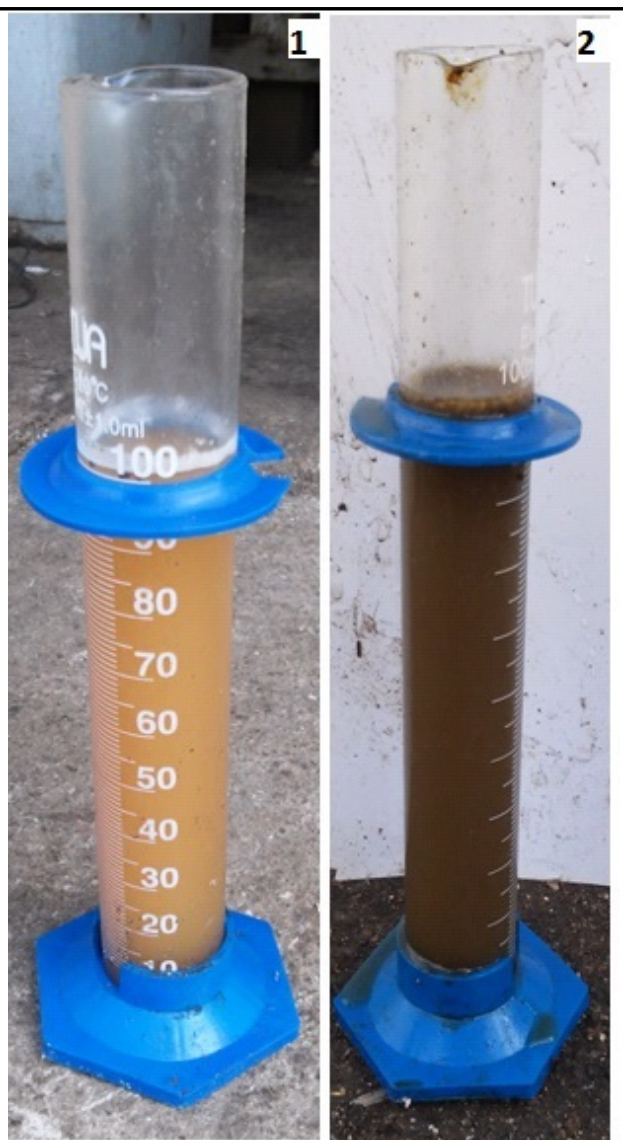

Figura 14: Cor do lixiviado no início $\left(\mathrm{n}^{\circ} 1\right)$ e fim do monitoramento $\left(\mathrm{n}^{\circ} 2\right)$

Os recalques iniciais dos resíduos analisados se manifestaram uma semana após a realização da camada de cobertura nos dois lisímetros. A rapidez do experimento em manifestar os recalques está associada à presença de materiais facilmente degradáveis que se encontram em contínua transformação, que resultam em movimentação vertical de resíduos, e sucessiva variação no nível da camada de cobertura, concordando com a literatura (GOMES et al., 1997; MONTEIRO et al. 2006, DURAN, 2009, COMPARIN, 2011; BATISTA et al. 2013).

Na primeira semana do monitoramento os lisímetros 1 e 2 apresentaram recalques (média de cinco medições) de 6,3 e 7,4 cm, respectivamente. Na semana seguinte, os recalques foram de $8,7 \mathrm{~cm}$ no lisímetro 1 e $10,7 \mathrm{~cm}$ no lisímetro 2. Na terceira semana, os recalques foram 10,4 cm (lisímetro 1) e 13,5 cm (lisímetro 2). Na quarta semana, os recalques foram $11,4 \mathrm{~cm}$ (lisímetro 1) e $15,0 \mathrm{~cm}$ (lisímetro 2). Na quinta semana, os recalques foram 12,5 cm (lisímetro 1) e 15,5 cm (lisímetro 2). Na sexta semana, os recalques foram praticamente 
iguais à semana anterior: $12,5 \mathrm{~cm}$ (lisímetro 1) e 17,3 $\mathrm{cm}$ (lisímetro 2), como mostra a Figura 15, o que pode caracterizar o fim do processo.

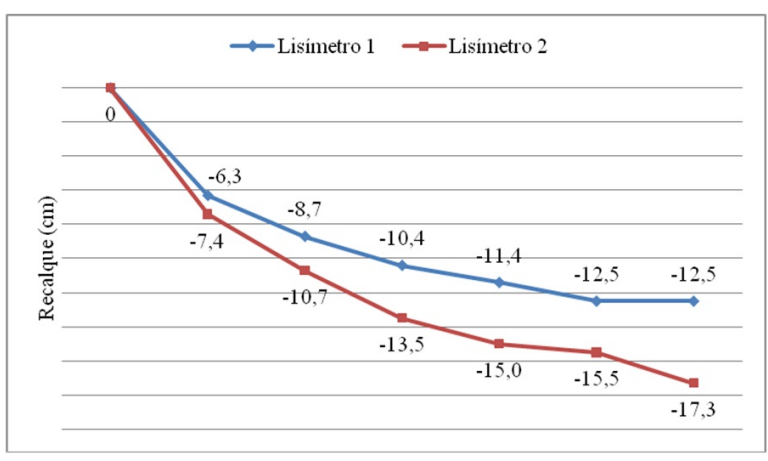

Figura 15: Comportamento dos recalques $(\mathrm{cm})$ nos lisímetros.

Como se observa, os recalques foram mais bruscos no início do monitoramento, concordando com a literatura (GOMES et al., 1997; MELO, 2003; DURAN, 2009). Monteiro et al. (2006), Duran (2009), Gamage et al. (2010), Comparin (2011), Batista et al. (2013) associam esse fato principalmente com fatores mecânicos: peso próprio da massa de resíduo, peso da camada de cobertura e sucessivo processo de preenchimento dos vazios a partir da expulsão dos líquidos e gases.

Segundo Melo (2003), os recalques iniciais são de grandes proporções, associados à aplicação de sobrecargas, já os recalques secundários se caracterizam pelo processo de deformação lenta, resultante do comportamento viscoso do resíduo e da perda de massa devida aos processos de biodegradação. Esse comportamento foi perfeitamente verificado nesta pesquisa, principalmente quando se observa que a diferença entre os recalques foi diminuindo de uma semana para outra, ou seja, ao longo do monitoramento.

Para Duran (2009), o conteúdo, o fluxo de umidade e a própria composição dos resíduos devem ser considerados nos recalques secundários, bem como, a sua compactação inicial. Ainda segundo o autor, a existência de recalques pode melhorar as propriedades dos resíduos sólidos dispostos à medida que aumenta a resistência mecânica dos mesmos, melhora a estabilidade do maciço e permite nova disposição. A Figura 16 exemplifica que os recalques permitiriam uma nova disposição de restos de alimentos no experimento caso interessasse. Conforme concluiu Röhrs, Fourie e Blight (1998), ao melhorar a velocidade de degradação de um aterro, mais resíduos podem ser depositados.

Os dois lisímetros apresentaram recalques com comportamento crescente ao longo do tempo, mas o li-

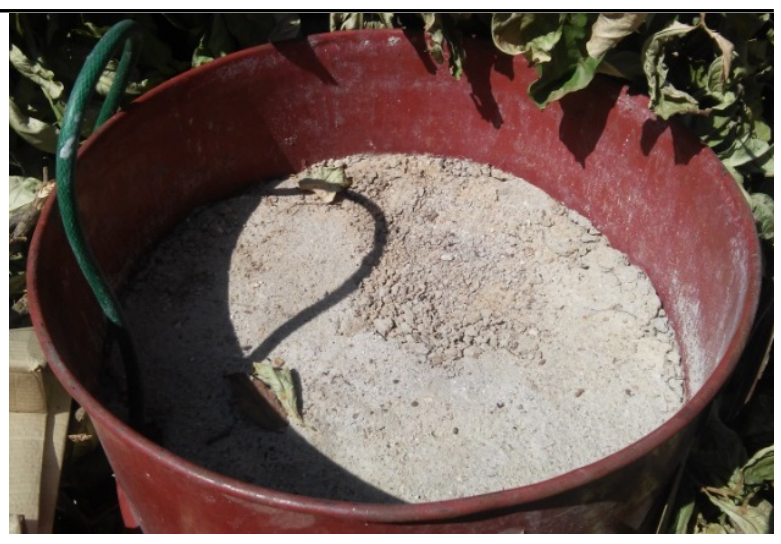

Figura 16: Vista dos pontos da medição dos recalques da camada de cobertura.

símetro 2 teve maior capacidade de manifestar tal propriedade, provavelmente em decorrência do fato dele ter gerado um maior volume de lixiviado no período, que ao sair pelo fundo do sistema (tambor) resultou em maior acomodação (recalque) das camadas superiores de resíduos. Conclusão semelhante foi feita por Vaidya (2002). O tamanho dos resíduos (DAMSIR, 2015) e sua composição (ZHENG et al., 2013) também influenciam a decomposição de resíduos em lisímetros.

\section{CONCLUSÃO}

Os resultados obtidos ajudam a entender o que realmente ocorre com a massa de lixo após compactação e confinamento, e isso contribui para uma criação de novas linhas de investigação sobre os processos relacionados à biodegradação de resíduos.

Os lisímetros de pequena escala se mostraram adequados, de baixo custo e sensíveis para medição dos processos físicos relacionados à degradação dos restos de alimentos, o que de certo modo elucida o que ocorre nos aterros sanitários e aproxima esses empreendimentos dos centros de pesquisa.

O controle sistemático da temperatura permitiu determinar, com segurança, o início e o fim das fases envolvidas na degradação dos resíduos: ajuste inicial, degradação ativa e maturação. Indiretamente, o monitoramento desse parâmetro em aterros sanitários pode revelar a fase de degradação do lixo.

Os dois lisímetros apresentaram temperaturas internas similares e dentro dos intervalos da literatura e mostraram correlação positiva entre os resultados da temperatura interna e o horário da medição ao longo do dia, mostrando influência do ambiente externo, algo já relatado na literatura. 
A exposição dos resíduos ao dia de chuva aumentou a geração de lixiviados em um dos lisímetros e isso mostra a importância de se realizar a camada de cobertura sobre os resíduos sólidos o mais rápido possível em pesquisas desse tipo e em aterros sanitários.

$\mathrm{O}$ volume de lixiviado ficou acima dos resultados da literatura provavelmente em função da presença de elevados teores de umidade nos restos de alimentos. Já o comportamento dos recalques - narrado na literatura - foi perfeitamente verificado nesta pesquisa, ou seja, mais bruscos no início do monitoramento e mais suaves nas semanas seguintes.

Diferentemente das demais pesquisas com lisímetros, esse experimento conseguiu mostrar como ocorre o processo de degradação dos restos de alimentos isoladamente, afinal são esses materiais que geram os lixiviados e os gases em aterros sanitários. Além disso, os lisímetros atuaram como biorreatores que aceleram a degradação de resíduos sólidos.

Trabalhos futuros podem simular esses processos de degradação com e sem a recirculação dos lixiviados, além de tamanhos e composições de resíduos diferentes.

\section{REFERÊNCIAS}

ALCÂNTARA, P. B. Avaliação da influência da composição de resíduos urbanos no comportamento de aterros simulados. 2007. $366 f$. Tese (Tese) Programa de Pós-Graduação em Engenharia Civil Universidade Federal de Pernambuco, Pernambuco, 2007.

ALVES, F. d. S. Influência das condições meteorológicas na biodegradação dos resíduos sólidos urbanos em Campina Grande - PB. Dissertação (Mestrado em Engenharia Civil e Ambiental) Pós-Graduação em Engenharia Civil e Ambiental, Universidade Federal de Campina Grande, Campina Grande - PB, 2012.

BARALDI, R. d. C. O. Efeito da recirculação de lixiviados na biodegradação de resíduos sólidos em uma célula do aterro da Muribeca - PE. Dissertação (Mestrado em Engenharia Civil) — Pós-Graduação em Engenharia Civil, Universidade Federal de Pernambuco, Recife, 2003.

BATISTA, L. S.; MELO, M. C. de; SOUZA, F. Q. de; MONTEIRO, V. E. D. Estudo de recalques e suas interações em uma célula experimental de resíduos sólidos urbanos. Revista Meio Ambiente e Sustentabilidade, v. 3, n. 2, p. 120-133, 2013.
CARVALHO, A. L. Efeitos da recirculação do percolado sobre a qualidade do efluente de lixo doméstico de diferentes idades. 2005. 116f. Tese (Doutorado em Engenharia Agrícola) - Universidade Federal de Viçosa, Viçosa - MG, 2005.

CHIEMCHAISRI, C.; CHIEMCHAISRI, W.; NONTHAPUND, U.; SITTICHOKTAM, S.

Acceleration of solid waste biodegradation in tropical landfill using bioreactor landfill concept. In: WASTE. 5th Asian Symposium on Academic Activities for Waste Management. Asian, 2002. p. 9-12.

COMPARIN, I. Estudo do comportamento de resíduos sólidos urbanos em lisímetro de caráter experimental. Dissertação (Trabalho de Conclusão de Curso (Graduação em Engenharia Ambiental)) Universidade de Passo Fundo, Passo Fundo, 2011.

CUNHA, E. R. Avaliação do processo de bioestabilização de resíduos sólidos urbanos em lisímetro de campo. Dissertação (Mestrado em Engenharia Civil) - Pós-Graduação em Engenharia Civil, Universidade Federal de Pernambuco, Recife, 2009.

DAMSIR. Anaerobic decomposition process characteristics of various sizes of garbage in a lysimeter system. Journal of Environment and Earth Science, International Institute for Science, Technology \& Education (IISTE), v. 5, n. 12, p. 25-31, 2015.

DURAN, C. A. Geração de biogás em ensaio de redução de volume por compressão em amostras de resíduo sólido domiciliar enfardado. Dissertação (Mestrado em Tecnologia Ambiental) — PósGraduação em Tecnologia Ambiental, Universidade de Ribeirão Preto, Ribeirão Preto, 2009.

ERSES, A. S.; ONAY, T. T.; YENIGUN, O. Comparison of aerobic and anaerobic degradation of municipal solid waste in bioreactor landfills. Bioresource technology, Elsevier, v. 99, n. 13, p. 5418-5426, 2008

FIRMO, A. L. B. Estudo numérico e experimental da geração de biogás a partir da biodegradação de resíduos sólidos urbanos. Dissertação (Doutorado em Engenharia Civil) — Pós-Graduação em Engenharia Civil, Universidade Federal de Pernambuco, Recife, 2013.

GAMAGE, D. A. S.; SARACHCHANDRA, G. W. N. L.; BASNAYAKE, B. F. A.; COSTA, W. A. J. M. Lysimeter smulation of paddy straw landfill bioreactor 
ESTUDO DO PROCESSO DE DEGRADAÇÃO DE RESÍDUOS SÓLIDOS ORGÂNICOS (RESTOS DE ALIMENTOS) EM LISÍMETRO DE PEQUENO PORTE

for optimum gas production. Tropical Agricultural Research, Postgraduate Institute of Agriculture, University of Peradeniya: Peradeniya, v. 21, n. 2, p. 177-188, 2010.

GARCEZ, L. R. Estudo dos componentes tóxicos em um biorreator de resíduos sólidos urbanos da cidade de Campina Grande-PB. Dissertação (Mestrado em Engenharia Civil e Ambiental) — Pós-Graduação em Engenharia Civil e Ambiental, Universidade Federal de Campina Grande, Campina Grande, 2009.

GIORDANO, G.; FILHO, O. B.; CARVALHO, R. J. Processos físico-químicos para tratamento do chorume de aterros de resíduos sólidos urbanos. Rio de Janeiro: Tecnologias Ambientais, 2011. v. 4.

GOMES, L. P.; CONCEIÇÃO, D. C. d.; FLECK, A. et al. Avaliação dos recalques em sistemas piloto de aterramento de resíduos sólidos urbanos. In: ABES. Congresso Brasileiro de Engenharia Sanitária e Ambiental, 19Feira Internacional de Tecnologias de Saneamento Ambiental, 2-FITABES'97. Foz de Iguaçu, 1997. p. 11.

JUCÁ, J.; MACIEL, F. Permeabilidade ao gás de um solo compactado não saturado. In: CBGE. $4^{\circ}$ Congresso Brasileiro de Geotecnia Ambiental. S. José dos Campos-SP, 1999.

JUNQUEIRA, F. F. Análise do comportamento de resíduos urbanos e sistemas dreno-filtrantes em diferentes escalas, com referência ao Aterro do Jóquei Clube. 2000. $283 f$. Tese (Doutorado em Engenharia Civil e Ambiental) - Universidade de Brasília, Brasília-DF, 2000.

KASAM. Effect of leachate recirculation on characteristics of leachate generation of municipal solid waste from landfill lysimeter. Journal of Chemistry and Chemical Engineering, David Publishing Company, Inc., v. 7, n. 5, p. 456-461, 2013.

LEITE, H. E. A. S. Estudo do comportamento de aterros de RSU em um biorreator em escala experimental na cidade de Campina Grande-PB. Dissertação (Mestrado em Engenharia Civil e Ambiental) - Pós-Graduação em Engenharia Civil e Ambiental, Universidade Federal de Campina Grande, Campina Grande, 2008.

MEIRA, R. C. Estudo biodegradativo dos resíduos sólidos urbanos da cidade de Campina Grande-PB em escala experimental. Dissertação (Mestrado em Engenharia Civil e Ambiental) - Pós-Graduação em
Engenharia Civil e Ambiental, Universidade Federal de Campina Grande, Campina Grande, 2009.

MELO, M. C. Uma análise de recalques associada a biodegradação no aterro de resíduos sólidos da Muribeca. Dissertação (Mestrado em Engenharia Civil) - Pós-Graduação em Engenharia Civil, Universidade Federal de Pernambuco, Recife, 2003.

MONTEIRO, V. E. D. et al. Estudo do comportamento de rsu em uma célula experimental e suas correlações com aspectos microbiológicos, físicos e químicos. Engenharia Sanitária e Ambiental, SciELO Brasil, v. 11, n. 3, p. 223-230, 2006.

QDAIS, H. A.; ALSHERAIDEH, A. Kinetics of solid waste biodegradation in laboratory lysimeters. Jordan Journal of Civil Engineering, v. 2, n. 1, p. 45-52, 2008.

RÖHRS, L. H.; FOURIE, A. B.; BLIGHT, G. E.

Effects of sewage sludge and refuse composition on the rate of degradation and leachate quality of co-disposed waste in a water-deficient environment. WATER SA, WATER RESEARCH COMMISSION-S AFRICA, v. 24, p. 137-146, 1998.

SANTOS, P. C. V. dos. Estudo da degradação e dos recalques em células experimentais de resíduos sólidos no aterro do Jockey Club/DF. Tese (Doutorado em Engenharia Civil e Ambiental) — Faculdade de Tecnologia da Universidade de Brasília., Brasília, 2004.

SANTOS, V. C. Projeto, construção e instrumentação de um lisímetro em escala de laboratório para estudos em resíduos sólidos. Dissertação (Trabalho de Conclusão de Curso (Graduação em Engenharia Ambiental)) — Universidade de Passo Fundo, Passo Fundo, 2010.

SIDA, s. i. d. c. a. Enhancement of Solid Waste Degradation Using Different Operating Techniques in Bioreactor Landfill. Bangkok, Thailand, 2004.

SILVA, A. K. M. d. Estudo do comportamento dos resíduos sólidos urbanos (RSU) em lisímetros preenchidos com resíduos de diferentes características. Tese (Doutorado em Saneamento Ambiental) Pós-Graduação em Engenharia Hidráulica e Ambiental, Universidade Federal do Ceará, Fortaleza, 2013.

SILVA, C. A. M. Costa e. Avaliação comparativa dos potenciais poluidores de lixiviados de resíduos sólidos domiciliares e de resíduos sólidos de serviço de saúde dispostos em células experimentais. Tese (Doutorado em Ciências) - Programa de Pós-Graduação em 
Tecnologia de Processos Químicos e Bioquímicos. Universidade Federal do Rio de Janeiro, Escola de Química, Rio de Janeiro, 2014.

SILVA, J. D. D. Monitoramento da geração de líquidos percolados em instalações experimentais pelo método do balanço hídrico. Dissertação (Mestrado em Engenharia Ambiental) — Pós-Graduação em Engenharia Ambiental, Universidade Federal de Santa Catarina, Florianópolis, 2002.

SIMÃO. Construção de um biodigestor de baixo custo e sua produção inicial. In: FATEC. Jornada Científica E Tecnológica Da Fatec. Botucatu, 2014.

SOUSA, G. d. Monitoramento de parâmetros qualitativos e quantitativos de líquidos percolados de aterros sanitários - estudo em piloto experimental. Dissertação (Mestrado em Engenharia Ambiental) - Pós-Graduação em Engenharia Ambiental, Universidade Federal de Santa Catarina, Florianópolis, 2005.

TEIXEIRA, E. . N. Efeito Inibidor da Recirculação Direta de Chorume na Decomposição Anaeróbia de Resíduos Sólidos. Tese (Tese de Doutorado em Hidráulica e Saneamento)) — Pós-Graduação em Engenharia, Escola de Engenharia de São Carlos-USP, São Carlos, 1993.

TEIXEIRA, E. N.; PANSANI, A. Avaliação do potencial poluidor/contaminador de aterros em vala (aterros manuais). In: FEMISCA. Congreso Interamericano de Ingeniería Sanitaria y Ambiental, 28. Porto Alegre, Brasil, 2002. p. 1-8.

VAIDYA, R. D. Solid waste degradation, compaction and water holding capacity. Tese (Master of Science in Environmental Engineering) - Faculty of the Virginia Polytechnic Institute and State University, Blacksburg, Virginia, 2002.

ZHENG, W.; PHOUNGTHONG, K.; LÜ, F.; SHAO, L.-M.; HE, P.-J. Evaluation of a classification method for biodegradable solid wastes using anaerobic degradation parameters. Waste management, Elsevier, v. 33, n. 12, p. 2632-2640, 2013. 